\title{
The Effects of a Low-Dose Intravenous Insulin Infusion Upon Plasma Glucose and Non-Esterified Fatty Acid Levels in Very Obese and Non-Obese Human Subjects
}

\author{
S. M. Bakir ${ }^{1}$ and R. J. Jarrett ${ }^{2}$ \\ 'Unit for Metabolic Medicine and 2Department Community Medicine, Guy's Hospital, London, England
}

Summary. After an overnight fast, the effects of a $30-$ min low-dose intravenous insulin infusion (2.6 units/ h) upon plasma glucose and non-esterified fatty acids were compared in 29 very obese patients and 17 nonobese controls. The dose of insulin was chosen so as to have its sole or predominant hypoglycaemic effect upon hepatic glucose release. The proportional fall from basal values at $30 \mathrm{~min}$ of both plasma glucose and non-esterified fatty acids was significantly greater in the controls and there was no difference between males and females. In the controls the fall in plasma glucose and non-esterified fatty acids was significantly and inversely correlated with the basal plasma insulin level. Neither index of insulin sensitivity was significantly related with the basal plasma insulin in the obese subjects. Weight loss in the obese subjects led to increased insulin sensitivity; in particular, the degree of change in insulin-induced nonesterified fatty acids was significantly related to the percentage change in weight. Despite their extreme degree of obesity, the distributions of basal plasma insulin levels and the indices of insulin sensitivity in the obese subjects overlapped with those of the nonobese controls.

Key words: Insulin, obesity, blood glucose, plasma non-esterificd fatty acids, low-dose insulin infusion

Intravenous infusion of insulin at low dose rates, sufficient to raise fasting insulin levels two or threefold, have been shown to lower blood glucose levels in non-diabetics and diabetics primarily by reducing hepatic glucose release [1, 2]. We have used low dose infusions of insulin to study in vivo hepatic insulin sensitivity in obese and non-obese, non-diabetic sub- jects. Measurements of plasma non-esterified fatty acids (NEFA) were also performed to assess the peripheral effects of insulin. The effects of weight loss upon insulin sensitivity measured by these methods were studied in obese subjects only.

\section{Subjects and Methods}

The protocol was approved by the Guy's Hospital Ethical Committee. Patients attending the Obesity Clinic at Guy's Hospital were asked to volunteer for the study after an explanation of its nature and gave written consent. Non-obesc controls were members of the medical, technical and secretarial staff of the Department of Medicine. Reference data concerning patients and controls are given in Table 1. Clinically significant metabolic abnormalities associated with obcsity were excluded in the patients by measurcment of blood glucose and plasma cortisol and by tests of

Table 1. Some characteristics of the control and obese subjects

\begin{tabular}{|c|c|c|}
\hline Number & $\begin{array}{l}\text { Control subjects } \\
n=10\end{array}$ & $\begin{array}{l}\text { Obese subjects } \\
n=20\end{array}$ \\
\hline \multicolumn{3}{|l|}{ Female: } \\
\hline $\begin{array}{l}\text { Mean age (years) } \\
( \pm \text { SEM) }\end{array}$ & $29.6 \pm 2.7$ & $29.3 \pm 1.5$ \\
\hline Age range (years) & $22-52$ & $18-43$ \\
\hline Mean wcight (kg) & & \\
\hline$( \pm$ SEM) & $65.7 \pm 0.7$ & $104.4 \pm 4.1$ \\
\hline Weight range (kg) & $62-68$ & $79-140$ \\
\hline $\begin{array}{l}\text { Fasting plasma } \\
\text { insulin range (mU/1) }\end{array}$ & $1-14$ & $2-53$ \\
\hline Male: & & \\
\hline Number & 7 & 9 \\
\hline $\begin{array}{l}\text { Mean age (ycars) } \\
( \pm S E M)\end{array}$ & $28.8 \pm 3.2$ & $28.9 \pm 3.7$ \\
\hline Age range (years) & $21-46$ & $17-47$ \\
\hline Mean weight $(\mathrm{kg})$ & $66.1 \pm 3.4$ & $126.3 \pm 5.4$ \\
\hline Weight range (kg) & $56-78$ & $104-156$ \\
\hline $\begin{array}{l}\text { Fasting plasma } \\
\text { insulin range }(\mathrm{mU} / \mathrm{l})\end{array}$ & $1-9$ & $7-32$ \\
\hline
\end{tabular}


Table 2. Effects of insulin infusion upon blood glucose levels (mmol/1; mean $\pm \mathrm{SEM}$ )

\begin{tabular}{|c|c|c|c|c|c|c|c|c|}
\hline & \multicolumn{8}{|l|}{ Time (min) } \\
\hline & 0 & 5 & 10 & 15 & 20 & 25 & 30 & $30 \mathrm{~min} \%$ basal \\
\hline \multicolumn{9}{|l|}{ Female } \\
\hline Obese $(n=20)$ & $4.1 \pm 0.12$ & $4.0 \pm 0.15$ & $3.9 \pm 0.13$ & $3.7 \pm 0.14$ & $3.7 \pm 0.15$ & $3.5 \pm 0.13$ & $3.5 \pm 0.2$ & $85.9 \pm 2.99^{\mathrm{a}}$ \\
\hline Controls $(\mathrm{n}=10)$ & $3.6 \pm 0.06$ & $3.6 \pm 0.12$ & $3.5 \pm 0.12$ & $3.2 \pm 0.10$ & $3.0 \pm 0.11$ & $2.8 \pm 0.12$ & $2.6 \pm 0.15$ & $72.0 \pm 3.67$ \\
\hline \multicolumn{9}{|l|}{ Male } \\
\hline Obese $(\mathrm{n}=9)$ & $3.7 \pm 0.13$ & $3.5 \pm 0.15$ & $3.6 \pm 0.13$ & $3.5 \pm 0.10$ & $3.4 \pm 0.12$ & $3.4 \pm 0.13$ & $3.3 \pm 0.17$ & $88.4 \pm 2.86^{\mathrm{a}}$ \\
\hline Controls $(\mathbf{n}=7)$ & $3.8 \pm 0.09$ & $3.7 \pm 0.09$ & $3.6 \pm 0.09$ & $3.3 \pm 0.11$ & $3.1 \pm 0.12$ & $2.9 \pm 0.1$ & $2.7 \pm 0.12$ & $71.8 \pm 2.99$ \\
\hline
\end{tabular}

a Difference from controls: $p<0.001$

Table 3. Effects of insulin infusion upon plasma NEFA levels ( $\mu$ mol/l; mean \pm SEM)

\begin{tabular}{|c|c|c|c|c|c|c|c|c|}
\hline & \multicolumn{8}{|l|}{ Time (min) } \\
\hline & 0 & 5 & 10 & 15 & 20 & 25 & 30 & $\begin{array}{l}30 \text { min } \\
\% \text { basal }\end{array}$ \\
\hline \multicolumn{9}{|l|}{ Female } \\
\hline Obese $(n=20)$ & $600.6 \pm 26.8$ & $612.8 \pm 32.7$ & $627.5 \pm 36.2$ & $626.1 \pm 40.5$ & $594.6 \pm 37.7$ & $583.4 \pm 39.2$ & $548.0 \pm 38.7$ & $91.2 \pm 4.9^{\mathrm{a}}$ \\
\hline Controls $(n=10)$ & $675.6 \pm 36.6$ & $603.2 \pm 48.7$ & $570.2 \pm 53.2$ & $542.6 \pm 51.9$ & $463.2 \pm 43.8$ & $415.0 \pm 47.8$ & $361.8 \pm 46.4$ & $53.5 \pm 6.6$ \\
\hline \multicolumn{9}{|l|}{ Male } \\
\hline Obese $(n=9)$ & $618.9 \pm 30.8$ & $633.0 \pm 32.3$ & $641.3 \pm 32.9$ & $586.7 \pm 32.3$ & $606.0 \pm 41.9$ & $614.0 \pm 41.6$ & $571.2 \pm 40.2$ & $92.7 \pm 6.1^{\mathrm{a}}$ \\
\hline Controls $(n=7)$ & $456.7 \pm 35.9$ & $384.3 \pm 50.0$ & $359.2 \pm 37.5$ & $311.0 \pm 39.4$ & $265.5 \pm 27.6$ & $239.7 \pm 29.3$ & $216.1 \pm 16.8$ & $47.3 \pm 6.2$ \\
\hline
\end{tabular}

a Difference from controls: $p<0.001$

thyroid and liver function. Before admission to the metabolic ward for the insulin infusions, patients were interviewed by a dietician and were instructed to continue their usual diet.

\section{Insulin infusion tests}

In the morning, after an overnight fast, an indwelling venous catheter was inserted in a vein in each arm, one for sampling and one for infusion. The cannulae were kept patent by small injections of $0.154 \mathrm{~mol} / \mathrm{l}$ sodium chloride solution. After a 30 -min basal period, monocomponent insulin (Actrapid) was infused at a constant rate of 2.6 units/h in saline/albumin solution for a 30 -min period. Venous blood was sampled at $-30,-20,0,5,10,15,20,25$ and $30 \mathrm{~min}$. The three pre-infusion values were used to calculate a mean basal level.

Whole blood glucose was measured in duplicate on a Technicon Auto-Analyser using glucose oxidase. Plasma insulin was measured by a double-antibody method [3] and plasma NEFA by the fluorimetric method of Carruthers and Young [4].

The obese patients were discharged from the metabolic ward after a further interview with the dietician who prescribed a hypocaloric diet in the proportions $40 \%$ carbohydrate, $40 \%$ fat and $20 \%$ protein. Patients were subsequently seen at approximately 2-week intervals in the obesity clinic, when dietary recommendations were reinforced. The insulin infusion test was repeated when weight loss exceeded $10 \%$ of initial weight or after $2-3$ months if weight loss had not reached this target level.

Statistical tests included paired and unpaired Student's $t$ tests and Wilcoxon's test for non-parametric variables where appropriate. Coefficients of correlation were calculated by the method of least squares, using a programmed HP $983 \mathrm{~A}$ Calculator equipped with a plotter.

\section{Results}

The basal and post-infusion blood glucose values are presented in Table 2 and the percentage changes illustrated in Fig. 1. In the obese subjects, the effect of a 30 -min infusion was to lower the basal blood glucose level by approximately $12 \%$ on average compared with $28 \%$ in the controls, with no apparent sex difference in the response.

The plasma NEFA results are similarly presented in Table 3 and Fig. 2. In the controls the insulin infusion produced a proportionately greater fall in NEFA than in blood glucose, reaching approximately $50 \%$ of basal at the nadir. By contrast the effect in the obese subjects was less than that upon blood glucose and thus very much less than the NEFA fall in the controls.

Table 4 presents the basal and 30 min plasma insulin levels only, for plasma levels were virtually constant after $10 \mathrm{~min}$ of infusion. Mean basal levels were substantially higher in the obese subjects, though the distribution in obese subjects and their controls overlapped (Table 1). In the controls the proportional increase in insulin concentrations (three to fourfold) was greater than in the obese subjects, though the increments were similar and not significantly different. 

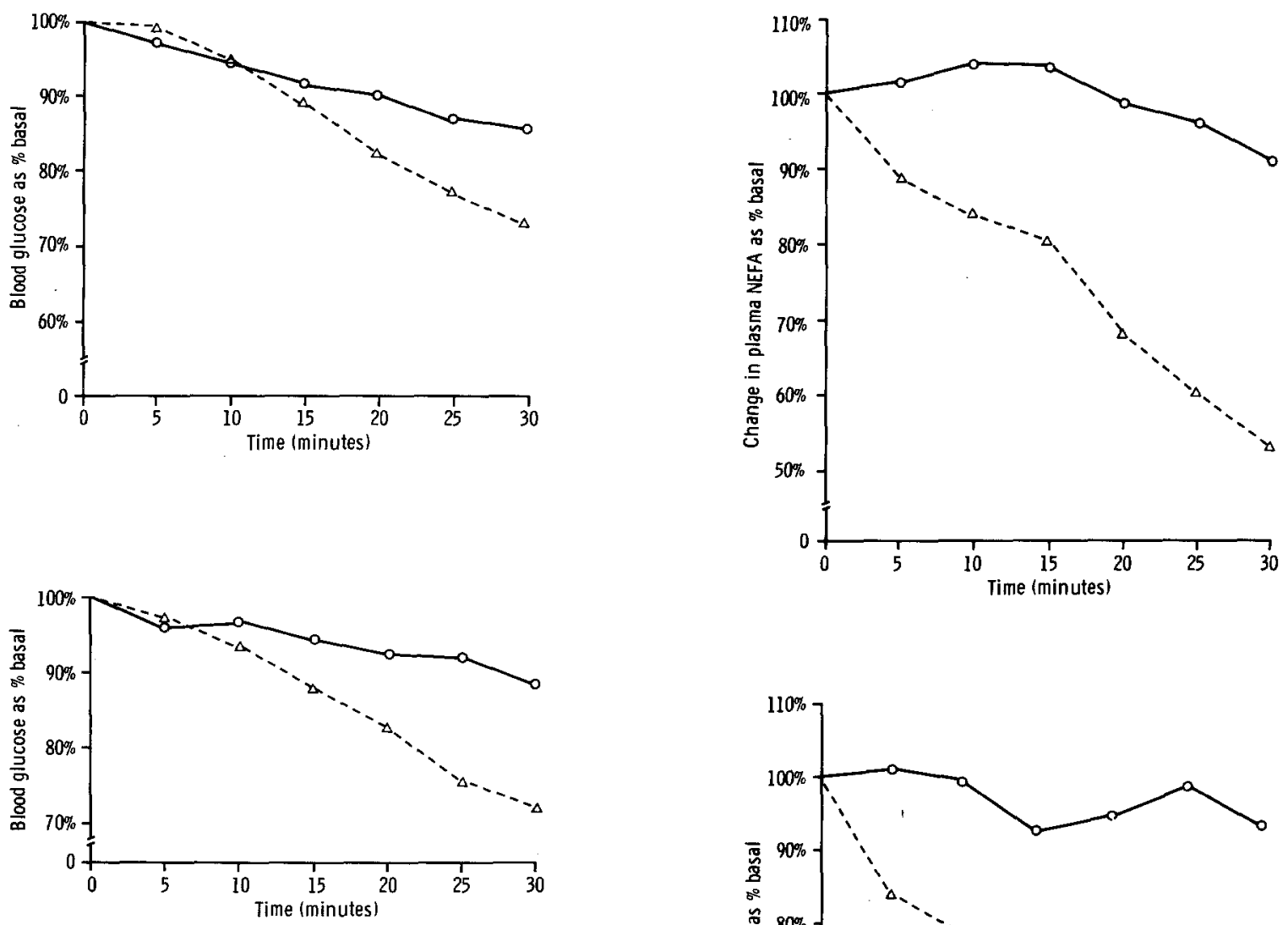

Fig. 1. Blood glucose level as percentage of basal during insulin infusion in obese and control subjects. Upper figure: females. Lower figure: males. $O-O$ Obese; $\triangle \longrightarrow \triangle$ Control subjects

Table 4. Plasma insulin levels before insulin infusion and at the end of the infusion (mU/1; mean $\pm \mathrm{SEM}$ )

\begin{tabular}{lrl}
\hline & Basal insulin & 30 min insulin \\
\hline Female & & \\
Obese $(n=20)$ & $17.6 \pm 2.7$ & $28.2 \pm 4.6$ \\
Controls $(n=10)$ & $5.4 \pm 1.1$ & $20.6 \pm 3.5$ \\
Male & & \\
Obese $(n=9)$ & $15.3 \pm 4.0$ & $29.5 \pm 7.0$ \\
Controls $(n=7)$ & $4.6 \pm 0.8$ & $16.2 \pm 2.9$ \\
\hline
\end{tabular}

The relationship between basal plasma insulin and the sensitivity to infused insulin as indicated by the percentage fall in blood glucose and plasma NEFA, respectively, was calculated. The results were similar in the two sexes and they were recalculated for both sexes combined. In the controls there was a statistically significant inverse relationship between basal plasma insulin and insulin sensitivity, i. e. the lower the basal plasma insulin, the greater the fall in blood glucose or plasma NEFA (blood glucose: $r=$

$0.61, p<0.01$; plasma NEFA: $r=0.50, p<0.05$ ). By contrast, neither index of insulin sensitivity was significantly related to basal plasma insulin in the obese subjects (blood glucose: $r=0.37,0.1>p>$ 0.05 ; plasma NEFA: $r=0.24, p>0.1$ ).

Effects of weight change: The obese patients who agreed to and subsequently had a second infusion test were arbitrarily classified into three groups according to their weight change following instruction in a hypocaloric diet: 
Table 5. Measurements made before and after dietary therapy in the three groups of obese patients

\begin{tabular}{|c|c|c|c|c|c|c|c|c|c|c|}
\hline \multirow[t]{2}{*}{ Groups } & \multicolumn{2}{|c|}{$\begin{array}{l}\text { Fasting } \\
\text { blood glucose } \\
(\mathrm{mmol} / \mathrm{l})\end{array}$} & \multicolumn{2}{|l|}{$\begin{array}{l}\text { Fasting } \\
\text { plasma NEFA } \\
(\mu \mathrm{mol} / \mathrm{l})\end{array}$} & \multicolumn{2}{|c|}{$\begin{array}{l}\text { Fasting } \\
\text { plasma insulin } \\
(\mathrm{mU} / \mathrm{l})\end{array}$} & \multicolumn{2}{|c|}{$\begin{array}{l}30 \mathrm{~min} \\
\text { blood glucose } \\
\text { (\% basal) }\end{array}$} & \multicolumn{2}{|c|}{$\begin{array}{l}30 \mathrm{~min} \\
\text { plasma NEFA } \\
\text { (\% basal) }\end{array}$} \\
\hline & Before & After & Before & After & Before & After & Before & After & Before & After \\
\hline A & $3.6 \pm 0.2$ & $3.6 \pm 0.55$ & $643.8 \pm 56.1^{\mathrm{a}}$ & $764.5 \pm 59.4$ & $27.9 \pm 7.6^{\mathrm{b}}$ & $15.1 \pm 5.1$ & $90.5 \pm 3.09^{b}$ & $73.2 \pm 3.76$ & $81.5 \pm 2.4^{b}$ & $70.6 \pm 3.5$ \\
\hline B & $4.27 \pm 0.24$ & $3.9 \pm 0.20$ & $643.8 \pm 48.6$ & $739.0 \pm 69.6$ & $21.9 \pm 4.8$ & $16.5 \pm 2.0$ & $96.4 \pm 2.6^{c}$ & $79.2 \pm 2.7$ & $96.4 \pm 1.7^{\mathrm{c}}$ & $79.2 \pm 1.3$ \\
\hline $\mathrm{C}$ & $3.7 \pm 0.11$ & $4.1 \pm 0.3$ & $604.0 \pm 88.2$ & $473.5 \pm 144.0$ & $9.7 \pm 3.2^{\mathrm{a}}$ & $22.9 \pm 7.1$ & $75.0 \pm 2.8$ & $77.0 \pm 2.96$ & $83.4 \pm 1.8^{b}$ & $93.8 \pm 1.7$ \\
\hline
\end{tabular}

Values are means \pm SEM

Group $\mathrm{A}=$ weight loss $>10 \%$ of starting weight; group $\mathrm{B}=$ weight loss $1-10 \%$ of starting weight; group $\mathrm{C}=$ gained weight

a $p<0.05 ;{ }^{\mathrm{b}} p<0.01 ;^{\mathrm{c}} p<0.001$ (paired t or Wilcoxon's tests).

A. Weight loss of $>10 \%$ of starting weight (mean weight loss $=13.9 \mathrm{~kg}$; mean age $=29.4$ years; $\mathrm{six}$ women, one man).

B. Weight loss $1-10 \%$ of starting weight (mean weight loss $=6.3 \mathrm{~kg}$; mean age $=33$ years; four women, three men).

C. Weight gain (mean weight gain $=8.2 \mathrm{~kg}$; mean age $=28.6$ years; two women, one man).

For the comparison before and after dieting, the results for both sexes have been combined. The mean level of fasting blood glucose showed little change in any group. In groups A and B there was a significant increase in the percentage fall in glucose and in the proportional fall in NEFA after weight loss (Table 5). When all the obese subjects were considered, there was a significant correlation between percentage change in plasma NEFA fall after insulin and percentage change in weight $(r=0.54, p<$ 0.05 ). The correlation between percentage blood glucose fall and percentage weight change was also positive, but not statistically significant $(r=0.28$, $p>0.1$ ).

Basal plasma insulin levels fell in both groups, $A$ and $\mathrm{B}$, but the difference was statistically significant only in Group A (Table 5).

\section{Discussion}

The insulin infusion rate used in this study was chosen on the basis of the observations of Brown et al. [1], confirmed by Sacca et al. [2], that the predominant effect of a low dose insulin infusion is upon hepatic glucose release rather than peripheral glucose uptake. In the obese subjects the effect of a 30-min infusion was to lower basal blood glucose by approximately $12 \%$, significantly less than the $28 \%$ in nonobese controls. Assuming that the observations of Brown et al. [1] and Sacca et al. [2] can be extrapo- lated to obese subjects, these results suggest a degree of hepatic insulin insensitivity in obese subjects, a finding in agreement with those of Felig et al. [5, 6].

In the controls, the insulin infusion had a much greater proportional effect upon plasma NEFA levels, with a maximal fall to $50 \%$ of basal. By contrast, the effect in the obese subjects was less than that upon blood glucose and thus very much less than the response in the controls. Rabinowitz and Zierler [7] reported that the effects of insulin upon peripheral metabolism are, at a given dose, more apparent upon NEFA release by cells than upon glucose uptake. Our results in the control group are in agreement with their observations.

Nestel and Matar [8] first showed that infusion of insulin produces a lesser fall in plasma NEFA in obese subjects than in non-obese controls, though they used a substantially higher dose of insulin. This effect appears to be a peripheral one, for the extraction of NEFA from the circulation by the liver is actually increased in obese subjects [5]. Nestel et al. [9] have produced further evidence that the defect in obesity is a relative failure of cells - probably muscle cells - to respond to the usual insulin stimulation of NEFA re-esterification.

West et al. [10] showed that, in non-obese subjects, the insulin sensitivity in terms of blood glucose fall could be predicted from the basal plasma insulin level. The same phenomenon was observed in our non-obese controls, both for blood glucose and plasma NEFA decline. However, in the obese subjects, individual insulin insensitivity was not significantly related to the basal plasma insulin level. Insulin insensitivity, at least as measured in this study, appears to be a function of the obese state rather than the degree of fasting insulinaemia. This is at variance with the results of Harrison et al. [11] who used a much larger insulin dose $(0.1 \mathrm{U} / \mathrm{g})$ and thus presumably measured both peripheral and hepatic 
insulin effects. In the present study (data not shown) increasing adiposity (measured as Body Mass Index) [12] did not significantly affect hepatic insulin sensitivity either in controls or obese subjects, though it was significantly related to NEFA fall in the controls. The effect just escaped statistical significance in the obese subjects. It may be relevant that weight loss in the obese had more effect upon NEFA fall than glucose fall during insulin infusion.

It now seems probable that the abnormalities in insulin receptors observed in obese humans and experimental animals are the result of hyperinsulinaemia rather than its cause $[13,14]$. Nevertheless, the obese subjects in the present study with 'normal' basal insulin levels were as insulin insensitive as those with high basal insulin levels. As with the latter, however, there was overlap with the controls in terms of both hepatic and peripheral insulin sensitivity. Thus, extreme obesity can occur without basal hyperinsulinaemia and without insulin insensitivity.

Olefsky [15] has drawn attention to a sub-group of "non-hyperinsulinaemic" obese subjects, claiming that they were younger, with onset of obesity in childhood and distinguished by the presence of 'hyperplastic' rather than 'hypertrophic' obesity. Baxter et al. [13] could not confirm this distinction and the obese subjects in the present study with basal insulin levels in the range of the controls had a mean age of 27.8 years, hardly different from those with elevated basal insulin values - mean age 29.8 years. Estimation of duration of obesity is imprecise, but we did not find any significant difference in duration of obesity in the two groups.

Obese humans are more likely to have raised basal plasma insulin levels and to show evidence of insulin insensitivity, though either may occur independently of the other and neither is an inevitable accompaniment of the obese state.

Acknowledgements. We wish to thank the volunteers who participated in this study and Mr. K. Kilbourn and the staff of the metabolic ward for technical and nursing assistance. Dietary advice was provided by Helen Powell and Valerie Meilton. The insulin measurements were performed in the laboratory of the Diabetes Research Unit at the Wellcome Foundation. The material in this paper forms part of a Ph. D. presented to and accepted by the University of London by S. M. B. who was supported by a grant from the University of Baghdad.

\section{References}

1. Brown P.M, 'Tompkins CV, Juul S, Sonksen PH (1978) Mechanism of action of insulin in diabetic patients: a dose related effect on glucose production and utilisation. $\mathrm{Br}$ Med J 1: $1239-1242$

2. Sacca L, Sherwin R, Hendler R, Felig P (1979) Influence of continuous physiologic hyperinsulinemia on glucose kinetics and counter-regulatory hormones in normal and diabetic humans. J Clin Invest 63: 849-857

3. Hales CN, Randle P (1963) Immunoassay of insulin with insulin antibody precipitatc. Lancet 1:200

4. Carruthers M, Young DAB (1973) Frce fatty acid estimation by a semi-automated fluorimetric method. Clin Chim Acta 49: 341-348

5. Felig P, Wahren J, Handler R, Brunden J (1974) Sphanchnic glucose and aminoacid metabolism in obesity. J Clin Invest 53 : $582-590$

6. Felig P, Wahren J (1975) The liver as site of insulin and glucagon action in normal, diabetic and obese humans. Isracl J Med Sci 2: 528-539

7. Rabinowitz D, Zierler KL (1962) Forearm metabolism in obcsity and its response to intra-arterial insulin. J Clin Invest 41: 2173-2181

8. Nestel PJ, Matar K (1966) Relationship between resistance to insulin and body weight. Aust Ann Med 15: 301-304

9. Nestel PJ, Ishikawa T, Goldrick RB (1978) Diminished plasma free fatty acid clearance in obese subjects. Metabolism 27: $589-597$

10. West TE, Owens D, Sonksen PH, Srivastava MC, Tompkins CV, Nabarro JDN (1975) Metabolic responses to monoconponent human insulin infusions in normal subjects and patients with liver and endocrine disease. Clin Endocrinol 4: 573-584

11. Harrison LC, Martin FIR, Melnick RA (1976) Correlation betwcen insulin receptor binding in isolated fat cells and insulin sensitivity in obese human subjects. J Clin Invest 58: 1435-1441

12. Keys A, Fidanza F, Karvonen MJ, Kimura N, Taylor HL (1972) Indices of relative weight and obesity. J Chron Dis 25: 329-343

13. Baxter D, Stanton K, Lazarus NR, Keen $\mathbf{H}$ (1978) The relation between insulin and adipocyte insulin reccptors during treatment of human obesity. Eur J Clin Invest 8: 361-372

14. Wigand CP, Blackard WG (1979) Down regulation of insulin receptors in obese man. Diabetes 28: 287-291

15. Olefsky JM (1976) Decreased insulin binding to adipocytes and circulating monocytes from obese subjects. J Clin Invest 57: $1165-1172$

Received: 18 December 1980

and in revised form: 5 February 1981

Dr. R. J. Jarrett

Department of Community Medicine

Guy's Hospital Medical School

London SE 1

England 